DOI: $10.20472 /$ IAC.2018.038.026

\author{
TIIU PAAS \\ University of Tartu, Estonia
}

MARYNA TVERDOSTUP

University of Tartu; Innsbruck University , Estonia

\title{
SKILLS HETEROGENEITY AND IMMIGRANTS-NATIVE WAGE GAP IN EUROPEAN COUNTRIES
}

\begin{abstract}
:
Theoretical background and aim of the study. Theoretical framework for studying immigrants-native wage gap relies on the classical human capital theory, stating that differences in individuals' education and skills transmit into wage. Due to a lack of appropriate data, previous studies mostly approximated human capital with formal education to measure wage gap and occupation-qualification match. This paper aims to extend the knowledge on how individuals' skills and, particularly their use in European labour markets, contribute to the immigrants-native wage gap. This knowledge can contribute to the policy debate on the immigrants' integration in the host labour markets by offering a novel evidence on immigrants' skill profiles and their current (under)use in the European labour markets.

Data and methodology. Empirical part of the study bases on the OECD Program of International Assessment of Adult Competencies (PIAAC) data. We implement the multivariate regression analysis in the pooled and country specific samples. To precisely measure the individual human capital, we incorporate a formal education, literacy and numeracy skills, as well as the extent of cognitive skills use at work and in everyday life.

Empirical results. On average, foreign-born respondents achieve substantially worse scores in literacy and numeracy skills, comparing to natives. Only highly educated immigrants reveal skill improvement over immigration tenure. There are systematic and statistically significant differences in skill application at work across immigrants and natives. Although, once immigrants attain comparable to natives' skill use frequency, their pay disadvantage turns statistically insignificant, even among low and medium educated foreign-born. To further support the robustness of the results, we present the effects of immigration tenure on skill level and replicate the immigrant wage gap analysis in country-specific samples.

Conclusions and policy implications. The estimation results are stable leading us to the conclusion that potential for development and utilization of immigrants' human capital is still underused in the European labour markets. This suggest that an underuse of immigrants' skills and competencies is an important dimension of the immigrants' integration issue. The policy measures, having a potential to foster immigrants' skill use, include: development of the institutional framework improving qualified immigrants access to more challenging and highly rewarded jobs; improving the information system allowing immigrants to be better familiar with local labour markets; avoiding possible reasons for labour and housing markets' segregation; supporting socio-cultural integration of people with different ethnical background.
\end{abstract}

\section{Keywords:}

human capital, immigrants-native wage gap, PIAAC, European countries 
JEL Classification: J21, J24, 015 